\title{
7
}

\section{Strategy to Approach Sustainability in Companies: A Step by Step Model}

Quick Check-Is your company a sustainable company?

1. Is the product sustainable?

2. Is the production system sustainable?

3. Is the global value chain sustainable?

4. Is the business a good citizen and transparent on its activities?

If you want to evaluate if the company and employer is a sustainable company, I recommend the quick check below. This "tool" is inspired by Jeffrey Sachs, professor at Columbia University and key actor in the development of the UN Sustainable Development Goals (SDGs). In the rest of this chapter, I will present a strategy for how to actually realize the potential of being sustainable and profitable company.

How the approach to sustainable corporate responsibility starts is often dependent on individuals. Who this person is, its interest and engagement, whereabouts in the company, department, power to impact, responsibility, and so on, all have a great impact on how the company as 
a whole actually approach sustainability (Ditlev-Simonsen, 2010). If the person is head of marketing department, the approach to sustainability might be from a marketing perspective. Internal involvement and commitment might receive less attention. If it is somebody from the information and communication department picking up the issue, it might include more information in general-both internally and externally. If external investors ask for a sustainability report, the approach to sustainability might be shaped for investors, or department of accounting. The approach will then probably be more on reporting backwards, that is, things that have already happened, not visions and forward looking strategies. In Chap. 5, I reviewed what often is the corporate sustainability approach-in this section, the focus will be on what the strategy ought to be.

The following six steps, presented in Fig. 7.1, will guide companies on how to approach social responsibility and sustainability (DitlevSimonsen, 2013).

\section{ANCHOR in top management}

6.

2.

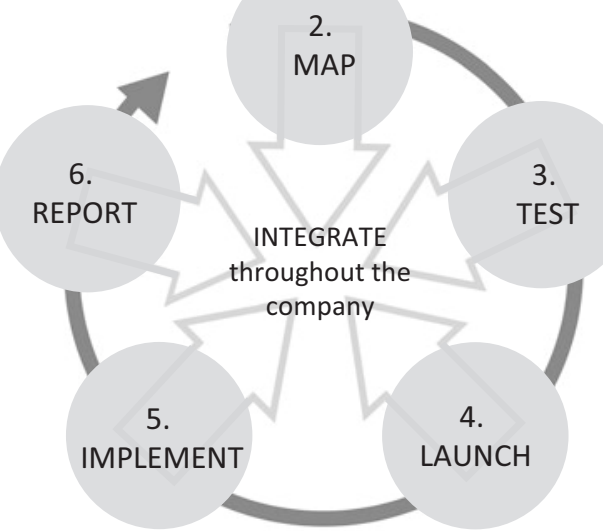

Fig. 7.1 Sustainability strategy model 


\subsection{Step 1: ANCHOR in Top Management and INTEGRATE Throughout the Company}

In order to approach sustainability strategically, the initiative needs to come from or at least be anchored in top management-or even betterrequested or endorsed by board of directors. Still, it is more common that an individual in the company takes the initiative. That is fine, but this person should get the message through to top management, not start a "local" project. As addressed earlier, it is important that the work on sustainability is integrated across the company. So, it is important also that the sustainability focus is not left at "the top" but involves all employees-or at least give them the opportunity to be involved.

Sustainability should not be an "add on" for the company but needs to be integrated throughout the company. It is not necessary with new channels for sustainability, but rather these activities should be integrated into already existing operations_-business development, marketing, customer communication, reporting employee bonus, and so on. Formulating a vision, purpose, or mission statement, explicitly expressing the company's commitment to sustainability is important. This can be done after Step 3 Test and set goals is completed. Examples of such corporate sustainability claims are presented in the Step 3 section. Corporate sustainability plans with concrete goals as well as visions and missions rarely go through without thorough work in top management and often requiring board approval. This strengthens the anchoring of sustainability in top management and commitment throughout the company.

\subsection{Step 2: MAP}

When the focus on sustainability is anchored in top management, getting an overview on the current status and draft plan for future work is necessary. Companies are complex organizations, and in order to get an overview of the company, it is useful to put together a task force to follow up 
the call from top management. As much as possible, the task force should represent all the divisions within a company-including representatives from HR, accounting, information department, and so on. It is important that the group is not too big in order to ensure good dialogue; it should be less than ten people. Still, I urge to allow other employees to contribute as well. Using a digital survey to announce the work and ask for input and comments is a simple and effective approach to collect relevant information and ensure buy-in.

The next involves mapping the company's social and environmental impact. If the company is in the oil and gas industry, relevant issues to address are for example $\mathrm{CO}_{2}$ emissions and HMS issues. If it is a small company in the textile industry, for instance, running a clothing store importing from Bangladesh or Cambodia, emissions associated with dyeing of textiles and working conditions among employees among the suppliers are more relevant. My experience with companies is that the first thing they are looking for is where the company is doing something good. They focus on that and not in the area where there are real problematic challenges facing the company.

"Did You Lose the Keys Here?" "No, But the Light Is Much Better Here" (Are your sustainability challenges in this area? No, but we have so much more nice things to tell from our activities in this area.)

Using the UN SDGs as a checklist is a good approach to mapping the current situation, opportunities, and challenges. Some of the 17 goals will be more relevant than others. Identify the goals that are the most relevant and depending on the size of the company, more of the goals can be selected. For small companies, it is perfectly fine to focus on one goal and how the company can contribute to that, whereas for larger companies, it can be useful to work with several goals. Some multinational companies choose to address all 17 goals_-and sometimes it seems like they want to "cover their backs" not to leave anything out.

A good approach to use in mapping the relative importance of different elements of the company's impact is through a materiality assessment. 


\section{Materiality Assessment}

Materiality assessment is a practical framework to discuss with colleagues and other stakeholders on what to prioritize and what matters for whom. Depicting the different items visually furthermore gives a good overview and basis for a sustainability program. It serves as a good decision tool. It is common to use materiality assessments in large companies, but it is also useful for small-to-medium enterprises (SMEs).

The materiality assessment concept consists of a matrix with two axes. The $\mathrm{x}$-axis addresses business impact/relevance, while societal and stakeholder impact/relevance is on the y-axis. In Fig. 7.2, the materiality model is presented. Depending on the impact on society and business, issues are placed at different areas on the matrix.

The unit of measurement on each of the two axes is Low and High. Issues in the Low-Low area are rarely put into the matrix. In this case, we are talking about issues which have a low impact on society and are low on relevance for business. An example could be a bakery located in

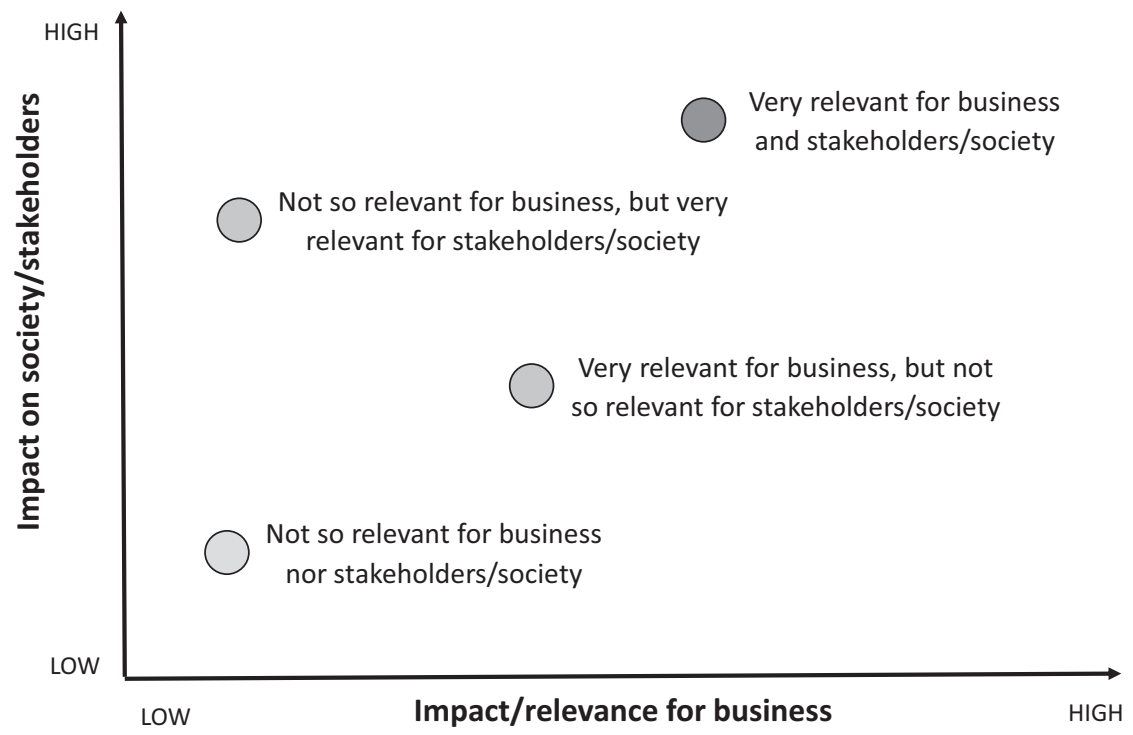

Fig. 7.2 Generic model for materiality assessment 
Norway making its own products. For this company, working conditions are strictly regulated by the Norwegian government. Customers are also not likely to be very concerned about employees' working conditions when they make purchases at the bakery. So low impact and low relevance should be placed in the Low-Low area. In the High-High area for the same bakery, the number of ingredients produced with low levels of pesticides would be an issue. Avoiding palm oil for example would be relevant and placed in the High-High area.

Unilever, a multinational consumer goods company, places climate change as a High-High issue, signaling that the company recognizes that climate change is very relevant for society and its stakeholders. It also signalizes that the company actually can contribute to the reduction of greenhouse gas (GHG) emissions. Unilever has set a target to move to zero emissions in its operations by 2030 , by among others decarbonizing raw materials, shifting to renewable energy, and eliminating deforestation in its supply chain (Unilever, 2020). The company perceives talent and development as very important (High), but with a low impact on society and stakeholders in general (Low).

Some companies post the relevant SDGs in their materiality matrix. Canon, a company providing network solutions for business, perceives its impact on Life in Water, SDG\# 14 as Low-Low. That makes sense as the company is not in the marine industry and its stakeholders are not specifically concerned about the marine impact of Canon's products and services. SDG\# 9 however, Industry, Innovation and Infrastructure, is perceived as High-High for Canon. Working to reduce the cost of making chips and helping to automate factories to improve productivity are in the scope of Canon's core business operations. This SDG goal is therefore important and relevant for Canon as well as their stakeholders such as customers (Canon Global, 2021).

In a company, not all employees or other stakeholders immediately agree on where the different issues should be places relative to importance. That is why materiality assessments are an important tool in evaluations on what really matters. This again will contribute to different stakeholders eventually having a common agreement on what happensand if they do not, they know where and how they disagree. 


\section{Current Situation and Goal Drafting}

After the key areas of environmental and social impact are identified and mapped, the company has to take account of what they are already doing in these areas-that is, the current status. Often companies realize that they are actually doing a lot in the pursuit of sustainability-they just do not call it sustainability or corporate responsibility.

Several companies which have come to me for advice are worried that all their competitors work on sustainable corporate responsibility but they themselves are not. After the mapping exercise, they get somewhat reassured when they become aware of the current situation on environmental and social issues within the company. Still, they also realize that they need to organize this work and put it into a system. Benchmarking or assessing the current situation in different areas of relevant sustainability issues in the company is addressed in Chap. 5.

Using a simple example, a transport company, whose main impact is through gasoline usage $\left(\mathrm{CO}_{2}\right.$ emissions), "Ignore" would be to not be aware of or address the issue at all. "React" would be to identify the issue, but not do anything. "Defend" would be to argue for no need to do anything (everybody else uses gasoline cars, it is too expensive to replace the transport cars, etc.). "Accommodate" would be to replace the gasoline cars with electric cars. And finally, "Proact" would be to reflect on ways to coordinate transport, share cars, pickup-sites, and so on.

The next step then is to set concrete goals associated to the areas where the company has major social and environmental impact. For example, training of employees in sustainability; number of hours within specific time, reduction of $\mathrm{CO}_{2}$ in tons within a certain set time, and so on.

Then the company's key social and environmental impact is assessed and a plan with concrete goals is put forward. Reduce $\mathrm{CO}_{2}$ emissions by $10 \%$ by 2023 , stop using plastic packaging by 2024, Meatless Mondays from 2022, and so on. It is important also to have some more far-reaching goals, maybe not reachable within time, but to stretch innovation. For a small clothing store, it could be that 20 percent of their sales should be used clothes within a year. For an oil company, it can be to be an oil-free energy company within 10 years. 
The next step is to consult with stakeholders to collect feedback on the plan.

\subsection{Step 3: TEST}

Stakeholders are crucial for companies, and their relevance is obvious. Still, companies often overlook the key stakeholders in the process of developing their sustainability plan. More emphasis is often on marketing the sustainability plan to stakeholders after the program is ready. However, if stakeholders are involved in the developing the program, or at least asked, the likeliness that they will buy-in is much greater.

It is the customers who know what they expect and prefer from the company, it is employees in the production process, who know how to make the production process more sustainable and it is the suppliers, who know the challenges and the solutions in the supply chain. Research shows that employees want to be more involved in the sustainability process than they actually are (Ditlev-Simonsen, 2012). Engaging employees and soliciting their feedback by for example asking which of the SDGs they think are relevant for their job can be quite useful for the company as well as getting employees onboard. A simple online survey to employees is all that is needed to collect the necessary information.

The success of the sustainability program is much more likely if the program is tested on stakeholders prior to launch. Stakeholder management is the topic of Chap. 8 , but the following are some examples of relevant stakeholders in different sectors and areas of business.

For a large company in the oil and gas industry, consulting environmental organizations, customers, suppliers, and employees in general could be some relevant stakeholders. A consultancy company could also be a relevant stakeholder.

For the small clothing store, asking the customers on their views as well as to check the relevance and possibility of their goals with their agent is a good approach. Maybe what the store asks from their agent, information on the working conditions in the producers' factories, is not 
possible to obtain. Still, raising the issues pushes the agent to follow up the request which itself has an impact. This should be included in the store's sustainability plan.

Present the plan with concrete goals for different and relevant stakeholders. Reflect on their comments and, most likely, you are inspired to make revisions. The final plan has to be approved by the top management-and preferably the board of directors too. Developing a revised company vision, mission, and purpose statement associated with sustainability can be an efficient approach to signaling new corporate priorities and values. The following are some examples of such statements in large corporations - the process is equally relevant in SMEs:

Bosch is committed to sustainability and constantly evolving in this respect. The corresponding strategic foundations are anchored in our "New Dimensions-Sustainability 2025" target vision.

Tesla mission — "To accelerate the world's transition to sustainable energy". Coca-Cola- "Our vision is to craft the brands and choice of drinks that people love, to refresh them in body $\&$ spirit. And done in ways that create a more sustainable business and better shared future that makes a difference in people's lives, communities and our planet."

Beyond Meat_- "We believe there is a better way to feed our future and that the positive choices we all make, no matter how small, can have a great impact on our personal health and the health of our planet. By shifting from animal to plant-based meat, we can positively impact four growing global issues: human health, climate change, constraints on natural resources, and animal welfare."

TATA "To be the most reliable global network for customers and suppliers, that delivers value through products and services. To be a responsible value creator for all our stakeholders."

Philip Morris Int.'s new vision being "A Smoke Free Future." VW Group "We are a globally leading provider of sustainable mobility." Northvolt_ "Our mission is to build the greenest battery in the world with a minimal carbon footprint and the highest ambitions for recycling to enable the European transition to renewable energy."

The next step then is to launch the sustainability plan and new vision. 


\subsection{Step 4: LAUNCH}

Many companies are very happy after developing a good sustainability strategy with concrete plans and goals. However, often it ends up therea good plan and that is it.

The launching process, making the plan and the responsibilities known among key stakeholders such as employees, suppliers, customers, officials, and so on, is as important as the plan.

There are many channels of communication-everything from including aspects of the plan on company indoor information screens, on products, to include as parts of bids and offers.

Educating and contributing knowledge to external stakeholders is relevant. Educating employees on how to increase sustainability focus and planning is also important. Employees need to know the reasoning behind changes associated with the pursuit of sustainability. In the clothing store example, making the store employees aware of the current situation and goals will make them proud of their workplace. It is a good pitch for sales and the employees will be good ambassadors for the store.

Many companies are eager to inform employees and other stakeholders on their sustainability engagement. My experience is however that if these activities are not impacting the receivers of the information, the receivers will not pick up on it. The information has to be based on communication and dialogue, especially with the employees.

\subsection{Step 5: IMPLEMENT}

The implementation process actually ensures that set goals are being realized and it is the foundation for actually making change happen. Sometimes, sustainability goals are not explicitly part of the job description of employees or part of the usual day-to-day operations. Therefore, follow-ups though dialogue and meetings are useful. The most efficient approach is to include the company's sustainability plan as part of other progress evaluations and follow-ups, like for example in sales and budgets. 
A good and efficient tool and checklist for implementation is Kotter's 8-Step Process for Leading Change (Kotter, 2012):

1. Create a sense of urgency-let employees, customers, and other stakeholders know that your sustainability program is important and need attention-link it to concrete issues.

2. Build a guiding coalition - pinpoint the stakeholders involved in the process of developing the sustainability plan - they are part of the team.

3. Form a strategic vision and initiatives-the focus on sustainability should be clearly expressed in the company vision and the initiatives are part of the sustainability strategy.

4. Enlist a volunteer army-involve employees as "ambassadors" and credit stakeholders involved in the sustainability plan.

5. Enable action by removing barriers-include elements from the sustainability plan in the procurement criteria.

6. Generate short-term wins-announce when goals in the sustainability plan are achieved, and even when you come half-way

7. Sustain acceleration - use the achievements as drivers and motivators for that it is possible

8. Institute change - the awareness and success of sustainability plan can have long lasting impact across the corporation-as well as customers and suppliers. Make it part of company policy.

It is to be expected that not all goals in the sustainability plan will be met, and even to discover that some of the set goals were not optimal after all. All this is part of a learning process and important to track. An open environment for employees to be able to report on challenges and voice new ideas or replacement of goals is crucial. Channels such as an e-mail address dedicated to such dialogue can be useful. Employees as well as other external stakeholders can use this venue to contribute with feedback. In large companies, set-up for reporting is a relatively simple process. For the small clothing store, having an email or Instagram site for feedback and suggestion can be a simple and good channel. This continuous dialogue with stakeholders is often forgotten - both in large and small companies.

The most efficient way to ensure implementation of the sustainability plan is, however, to include elements of it in the company's performance 
bonus system. When employees can document their work, reach the goals, and receive a bonus, that is a game-changer.

It is argued that there is a distinct difference to succeed leading a sustainability process relative to leading other corporate changes. Focus on authentic leadership theory has received increased attention. Authentic leadership is about leaders being aware of their moral attitudes and integrate these in their day-to-day work. Pursuing a sustainability venue requires that leaders are good role models. When the company, endorsed by company leaders, urges employees to avoid traveling by plane and the managers travel by private planes generates a dissonance. A leader that applies sustainability in his or her day-to-day behavior is a powerful way to make employees implement sustainable changes in their work (DitlevSimonsen, 2009).

\subsection{Step 6: REPORT}

The final step in this model is the reporting phase. Reporting on the sustainability plan together with the annual report is a good approach. This illustrates that sustainability is an integrated part of the company's performance. When companies started reporting on first environmental and later social and sustainability issues, the reports were often very separate from the annual report, likely because sustainability was not integrated in the company-but something separate.

Now more and more companies are integrating their non-financial reports in their annual report. The term non-financial report is in many ways a wrong reference to corporate performance on social and environmental issues, because it can definitely have a financial impact. Some companies apply the term "extra-financial reporting" which is a much better description.

Reporting on social and environmental issues with figures and numbers, like change of $\mathrm{CO}_{2}$ emissions in tons, percent of recycled material in products in tons, and so on show that the company is treating these issues as part of day-to-day operations. Companies should also report on goals, which were not achieved, and why it is so. As mentioned above, maybe the goals set were wrong or impossible. This should be part of a 
learning process. In line with transparency, challenges and problems should also be reported. Such openness truly shows that the company actually integrates sustainability into operations.

In the small clothing store, the goal to increase sales of reused clothing could have been set to 20 percent. It turns out that the increase of sales was only ten percent. Why was that so? One approach to find out is to ask the customers. This illustrates how measuring and addressing the results can help improve the company's performance.

When the first round of the Step-by-Step sustainability strategy is concluded, the process continues on from Step 1, updated with experience from the first round. Furthermore, some of the goals set in the first round could be long-term goals, which have to be followed up on again. For example, as mentioned previously several companies have set goals to be carbon neutral by 2030. The degree to which the company is on track has to be benchmarked and reported annually. Reporting is in itself often backward looking. Sustainability reports should also be forward looking, sharing goals to be reached in within different timeframes. Many of the sustainability goals need time to be reached. Becoming carbon neutral for what is today an oil and gas company will probably need decades.

\section{References}

Canon Global. (2021). CSR activities: Materiality and SDGs. https://global. canon/en/csr/sdgs/index.html

Ditlev-Simonsen, C. D. (2009). Fordrer det noe spesielt å lede en samfunnsansvarlig bedrift. Magma, 2, 22-33.

Ditlev-Simonsen, C. D. (2010). From corporate social responsibility awareness to action? Social Responsibility Journal, 6(3), 452-468. https://doi. org/10.1108/17471111011064807

Ditlev-Simonsen, C. D. (2012). The relationship between Norwegian and Swedish employees' perception of corporate social responsibility and affective commitment. Business \& Society, 54(2), 229-253. https://doi. org/10.1177/0007650312439534

Ditlev-Simonsen, C. D. (2013). Ny proposisjon om samfunnsansvarsrapportering. Magma, 2, 12-14. https://www.magma.no/ny-proposisjon-om-samfun nsansvarsrapportering 
Kotter, J. P. (2012). Leading change. Harvard Business School Press. Unilever. (2020, December 14). Unilever to seek shareholder approval for climate transition action plan.https:/www.unilever.com/news/press-releases/2020/ unilever-to-seek-shareholder-approval-for-transition-action-plan.html

Open Access This chapter is licensed under the terms of the Creative Commons Attribution 4.0 International License (http://creativecommons.org/licenses/ by/4.0/), which permits use, sharing, adaptation, distribution and reproduction in any medium or format, as long as you give appropriate credit to the original author(s) and the source, provide a link to the Creative Commons licence and indicate if changes were made.

The images or other third party material in this chapter are included in the chapter's Creative Commons licence, unless indicated otherwise in a credit line to the material. If material is not included in the chapter's Creative Commons licence and your intended use is not permitted by statutory regulation or exceeds the permitted use, you will need to obtain permission directly from the copyright holder.

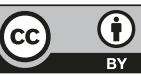

